\title{
O tráfico de escravos e a experiência diplomática afro-luso- brasileira: transformações ante a presença da corte portuguesa no Rio de Janeiro
}

Jaime Rodrigues*

Resumo. Neste artigo, retomo a tradição de negociações entre portugueses e diferentes povos do litoral africano em torno de questões relacionadas ao tráfico de escravos e à organização desse comércio. A partir dessa tradição, discuto as questões diplomáticas envolvendo africanos, portugueses, ingleses e brasileiros no contexto da vinda da Corte portuguesa para o Rio de Janeiro, em 1808, e nos anos que se seguiram, e a maneira pela qual os soberanos africanos foram afastados do processo de negociação que criaria restrições ao tráfico na primeira metade do século XIX.

Palavras-chave: Tráfico de Escravos. Diplomacia. África. Portugal. Brasil. Inglaterra.

Os tratados de comércio foram uma das estratégias utilizadas durante o processo de conquista e colonização de partes da África pelos portugueses. Ao longo de séculos, europeus e africanos acumularam experiências nos tratos comerciais, e quero aqui chamar a

* Professor de História do Brasil na Universidade Federal de São Paulo. 
O tráfico de escravos e a experiência diplomática afro-luso-anglo...

atenção para as embaixadas enviadas por soberanos africanos à América para cuidar desses assuntos. No que se referia aos reinos africanos ocidentais, essas experiências não se limitavam ao trato com os portugueses, que ocorriam pelo menos desde o século XVII e à ocupação holandesa em Pernambuco, quando uma embaixada do rei congo veio negociar com Maurício de Nassau, em Recife, no ano de 1643, como Gaspar Barléus menciona na História dos feitos recentemente praticados durante oito anos no Brasil.

A prática da negociação por meio de embaixadas era relativamente comum no Antigo Regime. Ainda que esta última expressão não dê conta de explicar a experiência africana de negociações com os europeus, em ao menos um aspecto esses dois povos pareciam ter entendimentos comuns, uma vez que, conforme Lara (2001, p. 151), "a pompa costumava revestir tais circunstâncias, já que se tratava de confirmar diante de todos não apenas a certeza da investidura dos emissários, mas, sobretudo, de ostentar o poder do monarca aí representado”.

Mas é preciso destacar que os acordos comerciais não se davam apenas entre os soberanos e seus prepostos, como nas embaixadas para a Bahia, entre 1750 e 1811, as quais serão abordadas mais adiante. Esses acordos eram feitos também entre particulares europeus e representantes dos reis africanos, como ocorreu desde que foram viabilizados os primeiros carregamentos de escravos com destino a Portugal e às ilhas, no século XV, e continuou a acontecer posteriormente com comerciantes europeus de outras nacionalidades, em negociações de maior ou menor êxito.

Os portugueses acumularam experiência em acordos desse tipo, firmados em território africano. Um deles, sobre o qual restaram algumas evidências, deu-se em torno da concessão da área para o estabelecimento de uma feitoria em Ngoyo/Cabinda, em 1783, antes do início da construção da fortaleza local. De um lado, estavam Antonio Januário do Vale, capitão da fragata N. S. da Graça, onde o acordo foi assinado, e o engenheiro militar Luís Cândido Furtado. De outro, o "Mambuco Muinspucula, príncipe e senhor 
das terras adjacentes à enseada e ao porto de Cabinda, o governador e príncipe Cafi, do mesmo porto, e seu manfuca Luifunga [...] e mais oficiais da sua corte". O acordo previa, além da instalação de uma feitoria de comércio na baía de Cabinda, a vassalagem das autoridades nativas à rainha de Portugal (D. Maria I), em troca da promessa de que os portugueses que "os insultarem ou por qualquer modo os maltratarem" ficariam sujeitos a penalidades. ${ }^{1}$

No entanto, cerca de um mês após a assinatura do documento, o governo colonial em Luanda reprovou os termos do acordo, pois se tratava de uma prova e de uma confissão de que os príncipes locais eram os verdadeiros senhores de Cabinda, ao passo que a Coroa portuguesa julgava-se soberana daquela área. Portugal não queria obter ali apenas a concessão de um estabelecimento comercial, pois isso não limitava o direito de os estrangeiros também fazerem o comércio de escravos naquele porto; o objetivo da Coroa era ver reconhecido seu domínio sobre aquelas terras.

Pouco depois da reprovação desse tratado, os portugueses voltaram a negociar com os africanos de Cabinda, dessa vez, em missão diplomática. Os termos foram expostos ao embaixador do mambuco em tom mais áspero, na tarde de 11 de novembro de 1783: ele deveria se converter ao catolicismo, render vassalagem a D. Maria I e fazer o comércio exclusivamente com os portugueses "somente agora no princípio", para, no futuro, admitir negócios com estrangeiros. Obviamente, tratava-se de uma estratégia para ganhar tempo e estabelecer um domínio efetivo sobre o lugar. Se não aceitasse as proposições do tratado, "tão úteis para a sua felicidade temporal e espiritual", o mambuco ficaria exposto

às hostilidades da guerra que lhes havemos de fazer, sujeitando à força das armas, e apesar de uma grande mortandade dos seus vassalos e ruína das suas povoações, tanto do mambuco como do rei de Cabinda, tendo a desgraça de perecerem às nossas mãos, arruinarem todo o seu comércio e interesse e ver reduzir a cinzas as suas moradas $[\ldots]^{2}$ 
O tráfico de escravos e a experiência diplomática afro-luso-anglo...

Apesar da demonstração de uma suposta força, a presença portuguesa em Cabinda não se fixou desde então. A fortaleza local, construída em 1783, foi destruída logo depois pelos franceses. O lugar ficou abandonado, sendo regularmente visitado por embarcações negreiras de outras nacionalidades.

Os acordos e as guerras envolvendo a posse de Cabinda no fim do século XVIII lançam uma luz sobre os interesses que se cruzavam quando se tratava de definir os poderes em uma área na qual o tráfico era tão ostensivo. A Coroa lusa, os senhores da terra, os franceses que faziam trocas nesse porto e mesmo os traficantes luso-afro-brasileiros aparecem como partes interessadas em definir a quem pertencia, afinal, aquele território.

Luanda reprovou os termos do acordo inicial com as autoridades de Ngoyo/Cabinda por enxergar nele apenas uma vantagem, que seria usufruída exclusivamente pelos traficantes - a pretendida feitoria. Nenhuma palavra do acordo fazia alusão ao domínio português efetivo ou à instalação de uma alfândega que arrecadasse tributos à Coroa, nem mesmo ao papel de Luanda e sua primazia no controle das demais áreas do litoral angolano. Os traficantes, por sua vez, diante da opção entre uma vassalagem fiel à Sua Majestade e um comércio vantajoso em Angola, ficaram com a segunda alternativa. Nessa e em outras oportunidades, eles deixaram claro que eram comerciantes cujo objetivo era abastecer navios negreiros para o Brasil e resistiram, sempre que pressionados a se submeter a novas taxas. Fixar o domínio português em Angola era tarefa na qual eles não pretendiam se empenhar de forma ostensiva, especialmente se tivessem que pagar por isso e encarecer o preço dos escravos que transportavam. Afinal, as possibilidades comerciais de Cabinda tinham sido "descobertas" pelos traficantes, presentes naquele porto antes de qualquer fortaleza ou outro estabelecimento da Coroa portuguesa.

Para os governantes de Ngoyo, discutir com os traficantes ou com as autoridades de Luanda parecia fazer pouca diferença. Seu objetivo era garantir o fluxo de escravos e as trocas comerciais, 
e eles estavam dispostos a negociar com quem oferecesse atrativos maiores, desde que não tivessem que abrir mão da soberania sobre o litoral. Por acreditarem que a insistência lusa os levaria a perder o controle da região litorânea, não tiveram problemas em unir-se aos franceses no ataque à fortaleza construída por militares portugueses em Cabinda, em 1783.

A negociação de tratados comerciais com os soberanos africanos pode dar a impressão de que essa prática garantia a paz no litoral da região congo-angolana. Mas essa impressão se desfaz facilmente quando se considera não só os termos duros dos acordos, nos quais Portugal sempre procurou impor seu domínio, mas também as repetidas vezes em que esses acordos eram simplesmente descumpridos pelos mesmos africanos que, algum tempo antes, haviam aceitado seus termos. Também é preciso levar em conta que os acordos criavam desconfianças entre os soberanos africanos que os assinavam e seus vizinhos, muitas vezes motivando ou acirrando conflitos entre eles.

Quando estouravam confrontos com os africanos, as conseqüências para o comércio eram imprevisíveis. É isso o que sugere, dentre outros documentos, o ofício enviado pelo governador de Angola, Antonio Saldanha da Gama, ao então Secretário de Estado dos Negócios Estrangeiros e da Guerra, Visconde de Anadia, em janeiro de 1808, no qual o primeiro afirmava manter a "quietação", tão necessária ao comércio no sertão de Angola, à custa de um destacamento militar e algumas peças de artilharia. Esse mesmo aparato garantia a chegada a salvo dos "embaixadores do grande potentado muata [soberano] Yanvo [dos lunda], que há tanto ambicionava o nosso comércio e que tinha sido embaraçado pelas nações limítrofes, cujos interesses ficavam sumamente lesados com esta comunicação [...]"3. Yanvo propunha a abertura de uma feira portuguesa, que não chegou a funcionar, "embora comerciantes portugueses tenham seguido, a partir de 1807-1808, as pisadas dos dois pumbeiros [os escravos angolanos Pedro João Batista e Amaro José]" (PÉLISSIER, 1986, p. 59), que chegaram à capital 
O tráfico de escravos e a experiência diplomática afro-luso-anglo...

dos lundas em 1806. O embaraço dos povos vizinhos (especialmente os de Cassange) à negociação do soberano lunda com os portugueses devia-se ao receio de perderem espaço no comércio de escravos, além do temor de verem o muata, fortalecido militarmente, voltar-se contra eles em busca de cativos para exportação.

As formas de organização e de reconhecimento do poder político dos povos do Congo e de Angola, talvez menos centralizados ou com um domínio restrito a áreas menores, podem ser uma das razões pelas quais conhecemos menos as negociações diplomáticas e comerciais entre eles e os portugueses. Mais conhecidas são as negociações envolvendo diversos soberanos da África Ocidental e autoridades coloniais portuguesas na América, que ocorreram pelo menos desde 1750, quando da primeira embaixada recebida pelo vice-rei português na Bahia. O fato era conhecido dos vice-reis posteriores, que sempre se remetiam ao tratamento dispensado à embaixada anterior, oferecendo, a cada novo embaixador, reverências cada vez menores. Essa primeira embaixada, a qual estou me referindo, enviada à Bahia pelo rei Tegbessu, do Daomé, em 1750, foi considerada uma "grande novidade, nunca vista no Brasill", repleta de pompas e cerimônias e incluindo caros presentes. Tratamento menos obsequioso receberam as demais embaixadas de reinos da África Ocidental, que sintomaticamente continuaram a seguir para Salvador, mesmo depois da transferência da capital colonial para o Rio de Janeiro, o que reforça o forte vínculo representado pelo tráfico tradicional entre as duas margens do Atlântico. Em 1795, Salvador recebeu os negociadores enviados pelo rei Agonglô, do Daomé, com o objetivo de oferecer aos traficantes baianos a exclusividade do comércio em Ajudá, seguindo-se ainda as embaixadas de 1805 (do Daomé) e de 1807 (de Onim, atual Lagos) (VERGER, 1987). Quando os reis de Ardra (Porto Novo) e Daomé enviaram simultaneamente suas embaixadas para tratar de questões do tráfico, em 1810, o que antes era chamado de "grande novidade, nunca vista no Brasil” já adquirira outro sentido: os embaixadores ficaram 
retidos em Salvador "tanto para não fazer despesas inúteis quanto para evitar de dar à população da capital [o Rio de Janeiro, agora capital do império] um espetáculo de novidade que teria provocado confusões" (VERGER, p. 279). A negociação ficou a cargo do Conde dos Arcos, então governador da Bahia, que foi instruído pelas autoridades da nova sede do império português a dispensar aos embaixadores "toda a atenção que pode merecer seu caráter, se a conduta deles for normal" (VERGER, p. 280).

Os embaixadores de Ardra e Daomé esperaram suas respostas por exatos dois anos. Chegados em 7 de setembro de 1810, foram dispensados em 10 de setembro de 1812, por orientação vinda da Corte carioca, que ordenou o transporte deles em condições decentes e confortáveis de volta aos seus países de origem (ibid., p. 282-283). Nesse meio tempo, no Rio de Janeiro, o Conde de Galvêas compreendeu que as pretensões de um opunham-se às do outro. O rei do Daomé oferecia exclusividade de comércio a Portugal (vale dizer, ao Brasil e especialmente à Bahia), enquanto o de Ardra propunha facilidades e "toda a qualidade de cooperação da sua parte", mas não exclusividade.

O oferecimento do Daomé não era novidade. Afinal, essa era uma da série de embaixadas que os soberanos desse reino enviaram ao Brasil (foram quatro no total, entre 1750 e 1811) e, já na segunda, em 1795, ofereciam a referida exclusividade de comércio, recusada por razões como a concentração excessiva de navios e a necessidade de abastecê-los em um mesmo lugar, a diminuição da liberdade dos mestres de escolher os escravos para compra e a elevação dos preços que um monopólio nas mãos do rei de Daomé acarretaria (VERGER, 1987, p. 266) Todavia, essa recusa reiterada podia gerar um conflito de interesses entre autoridades do Reino e colonos ou portugueses estabelecidos na Bahia. De um lado estava a Coroa lusa, que preferia ter múltiplas fontes de abastecimento de cativos sem prometer monopólio a nenhum soberano da África Ocidental, na medida em que suas feitorias litorâneas eram constantemente 
O tráfico de escravos e a experiência diplomática afro-luso-anglo...

atacadas, como ocorrera em Ajudá, em 1727, e em São João de Jaquim, em 1732, ambas ocupadas por forças do reino daometano em expansão sobre seus vizinhos. O Daomé manteve a concessão das feitorias, mas não a soberania portuguesa para organizar o comércio de escravos como lhe aprouvesse. De outro lado estavam os traficantes baianos, que tinham preferência evidente pelos escravos vindos da África Ocidental e, mesmo na época do tráfico ilegal, continuaram a abastecer Salvador, o Recôncavo e outras regiões com cativos embarcados no Golfo da Guiné.

As queixas do rei de Ardra contra o do Daomé e vice-versa, bem como as vantagens que ambos ofereciam, certamente visavam aos benefícios que poderiam obter no comércio de escravos a partir das transformações pelas quais ele passaria após o tratado firmado com a Inglaterra, em 1810. O Conde de Galvêas, após consultar o ministro dos Negócios Estrangeiros, garantia que "o nosso tráfico da escravatura deveria continuar não só naqueles portos pertencentes ao domínio de S.A.R. [Sua Alteza Real] e naqueles que se julgasse com direito à sua coroa, mas ainda em todos os mais em que os seus vassalos se achassem em posse de fazer aquele comércio". "O argumento era que o Brasil precisava aumentar seus braços e sua agricultura, como freqüentemente se afirmava nessa época, para justificar o tráfico. O regente português apenas expôs suas queixas em relação a alguns procedimentos do rei de Agomé, que dificultavam a ação dos comerciantes do império luso, mas não firmou compromisso com nenhum dos embaixadores.

Os termos do tratado de 1810 davam margem para a interpretação feita por Galvêas e pelo ministro português. Pelo acordo, "o Príncipe de Portugal se compromete a que seus vassalos não sejam mais autorizados a continuar o comércio de escravos em nenhuma parte da costa da África que não sejam atualmente possessões de Sua Alteza Real", o que poderia incluir Ajudá e Jaquim, pois, ainda que arrebatadas pelos daometanos havia décadas, esses portos não eram abertamente reivindicados por outras 
potências européias. ${ }^{7}$ De todo modo, os termos da negociação que desaguaria no tratado de 1810 já eram conhecidos anteriormente por alguns administradores coloniais portugueses, a julgar pela correspondência do citado governador de Angola, Saldanha da Gama, que, em agosto de 1807, fazia uma análise de conjuntura e aconselhava seus superiores em Lisboa:

Pelos papéis políticos de Inglaterra, julgo que a estas horas se achará proibido o comércio da escravatura naquele país. Nestas circunstâncias, e enquanto a França não tem meios de poder com franqueza aproveitar-se das vantagens que de alguns portos desta costa estas duas nações costumavam tirar, me parece que seria de suma utilidade apossarmo-nos de alguns pontos desta costa, que de direito nos pertencem, e onde já tivemos estabelecimentos, mas que por intrigas da Corte se tem demolido. ${ }^{8}$

Gama referia-se a Ambriz, na foz do Rio Loge, que já tivera um estabelecimento construído na época do governador Manuel de Almeida e Vasconcelos, posteriormente demolido, em função de negociações com a Inglaterra. Era hora de retomá-lo, considerando que estava em pauta a limitação do tráfico aos portos em que a soberania portuguesa fosse reconhecida - ainda que fosse preciso inventar essa legitimidade no último instante possível, antes de fechar acordo com os ingleses. Compartilhando a análise de Gama, Lisboa emitia, também em agosto de 1807, um alvará permitindo a um certo Boaventura José de Melo (que, suponho, fosse um traficante) o estabelecimento de uma feitoria no Cabo Negro (nas proximidades de Moçâmedes, atual Namibe, ao sul de Angola), apostando em mais um local promissor para o tráfico de escravos colocado debaixo da soberania portuguesa.

Os soberanos de diferentes reinos da África Ocidental, por sua vez, deram outras provas de que conheciam os termos do tratado assinado entre Portugal e Inglaterra e tomaram providências 
O tráfico de escravos e a experiência diplomática afro-luso-anglo...

para garantir a continuidade do tráfico, negociando diretamente com a Corte portuguesa, agora sediada no Rio de Janeiro. Adoxa, rei de Onim (Lagos), tentou fazer isso por meio de duas embaixadas à Bahia, entre fins do século XVIII e as primeiras décadas do século XIX, ao recorrer à antigüidade dos negócios realizados entre seus súditos e os europeus. A tradição multicentenária de trocas comerciais embasava seu argumento, pois elas já se faziam "no tempo dos meus antepassados, e do falecido meu pai o rei Logu; e também já no meu tempo antes dos ingleses impedirem às nações o comércio de escravos". 10

O que irritava Adoxa era o andamento das negociações entre ingleses e portugueses na questão do comércio africano, sem que ele (ou qualquer outro soberano africano) jamais fosse chamado à mesa do acordo - e vale dizer que esta é uma questão ignorada na maioria dos estudos sobre o tema. Quando avaliamos os relatos dos viajantes estrangeiros no litoral da África, podemos vê-los como portas de acesso para o universo dos conflitos presentes no tráfi$\mathrm{co}$, mas também como portas que, normalmente, ignoram a experiência africana nesse comércio. A reunião desses depoimentos de viajantes na criação de uma estratégia oficial de combate ao tráfico por parte dos ingleses talvez esteja na raiz do solene "esquecimento" dos africanos envolvidos no tráfico, deixados de lado quando se tratava de assinar acordos formais sobre a questão. Mais uma vez, a África era reduzida à visão de unidade desprovida de forma e especificidade, relegada a uma posição secundária no binômio "civilização $x$ barbárie". Sendo bárbaros, não havia porque convocar reis de qualquer território africano para uma decisão que envolvia princípios da civilização européia, como o empenho em acabar com o tráfico de escravos.

Mas Adoxa acreditava ter bons argumentos para debater, e o fato de estar sendo deliberadamente ignorado não escapou à sua percepção. Ele reagiu à possibilidade de ver desaparecer de seus portos os navios negreiros dos quais seu reino tanto dependia: 
Não me consta que nos portos declarados [Appé, Porto Novo e Badagri] [...] nenhuma destas nações fizesse tratado algum com os ingleses ou que lhe franqueassem o mais pequeno palmo de terra para sua habitação, sem que estivessem empregados no seu negócio, quanto mais para fazer um pequeno reduto em que pudessem cavalgar uma só peça e que por esta posse e título pudessem chamar os portos declarados acima seus domínios, e virem sem atenção tomar os navios de nação amiga e aliada, bem como aconteceu no meu porto que fizeram prisioneiros a três navios portugueses que se achavam a largar no dia seguinte e todos muito felizes [...] (ibid.).

Apesar da irritação, Adoxa fez um oferecimento concreto: franquear o litoral de seu reino, em nome dele e de seus sucessores, para que o soberano português mandasse "edificar quantos fortes quiser e terem o título de praias portuguesas, sem que para isso eu [Adoxa] queira tributo ou débito algum, só sim desejo à boa amizade e opulência do comércio [...]" (ibid.). O que talvez o rei de Onim não tivesse como saber ou não podia considerar era que, naquele momento, seu congênere português não tinha disposição, força ou condição de aceitar uma oferta tão generosa, indispondose com seu único aliado europeu fora do alcance das garras do império napoleônico, ao qual a Península Ibérica (e, de resto, quase todo o continente) sucumbira. De mais a mais, o tratado de 1810 era claro ao restringir o tráfico nos locais do litoral africano que não fossem, à época, possessões de Sua Alteza Real, e uma concessão extemporânea de Adoxa não colocaria suas praias na qualidade de praias portuguesas. Diante dessa situação, com o reino ocupado, manter os termos do tratado com a Inglaterra era a ordem do dia inescapável na agenda diplomática lusitana.

Se restringia o tráfico, o acordo não impedia que a bandeira portuguesa começasse a ser usada de forma indiscriminada por traficantes de diferentes nacionalidades, conforme denúncia do 
O tráfico de escravos e a experiência diplomática afro-luso-anglo...

ministro inglês no Rio de Janeiro, lorde Strangford. A denúncia era feita de acordo com as "bases imutáveis da humanidade e da razão", mas a razão lusa fazia entender que o acordo diplomático com os ingleses legitimava o tráfico em que a soberania de Portugal fosse reconhecida - e, de todo modo, o soberano português não poderia responder oficialmente pelo uso indevido da bandeira de seu reino por navios pertencentes a outros países.

A pressão britânica para que o tráfico terminasse na América portuguesa e, mais tarde, no Brasil, remonta à vinda dos Bragança e sua corte para o Rio de Janeiro. Um empréstimo de 600 mil libras, concedido ao governo luso, em 1809, foi seguido, em 1810, por já mencionados tratados de aliança, amizade, comércio e navegação que estabeleciam alguns princípios para uma futura abolição do tráfico.

Nos dois anos que se seguiram aos tratados, 17 navios foram capturados pela marinha inglesa, provocando reações dos negociantes da Bahia, a quem pertenciam 12 dos navios capturados, gerando prejuízos da ordem de 800 mil cruzados. Os atritos decorridos desse episódio chegaram a provocar ameaças aos navios ingleses ancorados no porto de Salvador.

As divergências em relação aos prejuízos causados por essas capturas seriam resolvidas em 1815, no Congresso de Viena. O governo inglês comprometia-se a indenizar o governo português em 300 mil libras pelos apresamentos, ao mesmo tempo em que renunciava ao recebimento do empréstimo de 600 mil libras, feito em 1809, e conseguia, por intermédio de um tratado firmado no mesmo Congresso, que o tráfico fosse abolido ao norte do paralelo do Equador. A proibição do tráfico com a região, que incluía as tradicionais fontes abastecedoras da Costa da Mina e do Ouro (atual Daomé e Nigéria, na África Ocidental) provocou novos e acirrados atritos entre os traficantes das capitanias e os ingleses nelas residentes. A continuidade do tráfico nas regiões ao norte do Equador seria, por muitos anos, motivo de conflitos e negociações entre os governos inglês, português e, posteriormente, brasileiro. 
A convenção adicional de 28 de julho de 1817 funcionou como uma regulamentação dos pontos firmados em 1815. Em seus itens principais, o novo acordo previa o direito recíproco de visita aos navios de ambos os países (Portugal e Inglaterra); o apresamento das embarcações que navegassem ao norte do Equador carregadas de africanos; a indenização por apresamentos indevidos; a proibição de capturas em águas territoriais de ambas as nações; e a criação de comissões mistas anglo-portuguesas no Rio de Janeiro, Serra Leoa e Londres.

Os termos desse novo tratado motivaram confrontos, que apareciam principalmente nas relações dos comerciantes da Bahia e do Rio de Janeiro. Tais confrontos punham em risco o patrimônio inglês no Brasil e revelavam a dificuldade dos governos português e brasileiro em fazer cumprir os compromissos assumidos. Tais dificuldades seriam acentuadas no reconhecimento da independência brasileira pelo governo inglês.

As negociações entre os plenipotenciários ingleses e portugueses vinham sendo encaminhadas desde 1808 pelo ministro do exterior Castlereagh. Após a morte deste e a ascensão de Canning ao posto, em que pesem as diferenças de origem e estilo existentes entre os dois, alguns princípios seguiram norteando a política exterior do gabinete conservador inglês. Um desses princípios aparece em carta ao Duque de Wellington, na qual Canning afirmava: "de uma coisa os Aliados podem estar perfeitamente seguros, é que nenhum estado do Novo Mundo poderá ser reconhecido pela Grã-Bretanha, senão tiver franca e completamente abolido o comércio dos escravos" (CANNING apud RODRIGUES, 1975, p. 16-17).

As conversações entre Inglaterra e Brasil prosseguiram até 1825, centradas na barganha entre o reconhecimento da independência e as garantias seguras da abolição do tráfico. Em 1823, Canning instruiu o representante inglês no Rio de Janeiro para que informasse o novo governo brasileiro a respeito dos princípios condenatórios ao comércio de escravos reafirmados em Verona, em fevereiro daquele ano. Nas conversações, não deveria haver: 
O tráfico de escravos e a experiência diplomática afro-luso-anglo...

um ar de ameaça ou de intimidação, mas simplesmente exprimir o desejo do governo britânico de que um gesto assim necessário fosse proposto por um ato voluntário do governo brasileiro, em antecipação ao desejo da GrãBretanha, antes de obter o resultado por outros meios. (VERGER, op. cit., p. 313).

O reconhecimento da independência do Brasil viria em 1825, seguido pelo tratado anglo-brasileiro de 13 de novembro de 1826, que previa o fim do tráfico de escravos em um prazo de três anos, mantendo os termos da convenção adicional de 1817. Ratificado pela Coroa inglesa em 13 de março de 1827, o novo tratado permitia a continuidade legal do tráfico até 13 de março de 1830. As repercussões do novo tratado foram enormes e marcaram profundamente as relações entre os governos brasileiro e inglês. ${ }^{11}$

Para além dos compromissos consignados nos acordos diplomáticos, o legado da presença da Corte portuguesa no Rio de Janeiro ao futuro estado nacional e à sociedade brasileira pode ser percebido em pelo menos dois outros aspectos relacionados ao tráfico de escravos africanos.

Em primeiro lugar (e devo dizer que a idéia não é originalmente minha, mas de Luiz Felipe de Alencastro), apenas passando rapidamente os olhos pelas estimativas de importação anual de africanos escravizados pelos portos do Brasil, é possível notar que os anos posteriores a 1808 marcaram um recrudescimento do tráfico, que só viria a cair a partir de 1831, para logo voltar a crescer, até 1850 . 


\section{Estimativas de importação de escravos - Primeira metade do século XIX}

\begin{tabular}{|c|c|}
\hline $1806-1810$ & 123.500 \\
\hline $1811-1815$ & 139.400 \\
\hline $1816-1820$ & 188.300 \\
\hline $1821-1825$ & 181.200 \\
\hline $1826-1830$ & 250.200 \\
\hline $1831-1835$ & 93.700 \\
\hline $1836-1840$ & 240.600 \\
\hline $1841-1845$ & 120.900 \\
\hline $1846-1850$ & 257.500 \\
\hline $1851-1855$ & 6.100 \\
\hline
\end{tabular}

Fonte: KLEIN, 1987, p. 58.

Esses dados permitem dizer que o legado da corte joanina não foi apenas marcado por iniciativas "civilizadoras" e européias, como a Biblioteca Nacional, a Missão Francesa, as academias de medicina e o Jardim Botânico, mas também pelo incremento da escravidão, na medida em que, a partir de 1808, cada vez mais africanos chegaram para trabalhar em diferentes partes do Brasil.

Por fim, a idéia de unidade territorial brasileira forjada a partir da vinda da Corte merece ser revista à luz dos tratados assinados com os ingleses e dos prejuízos que esses acordos trouxeram a traficantes de capitanias/províncias como a Bahia (caso estudado por Verger), Pernambuco e Maranhão, por exemplo. A exclusão de portos africanos que eram tradicionais fontes de escravos aos senhores dessas capitanias/províncias a partir dos acordos de 1810 certamente não contribuía para a unidade (e unanimidade) em torno do soberano português e do local da nova sede do poder central no império luso. O abandono de feitorias no litoral da África Ocidental, muitas delas propriedades de comerciantes luso-brasileiros, assim como o abandono da pretensão de soberania em pontos da costa naquela região do continente africano, mesmo que fosse 
O tráfico de escravos e a experiência diplomática afro-luso-anglo...

inevitável diante das circunstâncias e das alianças européias, também não foi um motivo de coesão dos interesses de senhores de terras e escravos das diferentes regiões da América portuguesa a partir da vinda da Corte ao Brasil.

The slave trade and the African-Anglo-Portuguese-Brazilian diplomatic experience: transformations during the presence of Portuguese Corte in Rio de Janeiro

Abstract. This article reiterate the tradition of negotiations between Portuguese and various African peoples on the coast of Africa, on questions related to the slave trade and the trade organization. From that tradition, I discuss diplomatic issues involving Africans, Portuguese, English and Brazilians in the context of the coming of the Portuguese court to Rio de Janeiro in 1808 and the years that followed, and the way in which the sovereign Africans were removed from the process of negotiation that would create restrictions on slave trade in the first half of the $19^{\text {th }}$ century.

Keywords: Slave Trade. Diplomacy. Africa. Portugal. Brazil. England.

\section{Notas}

1 “Termos do tratado entre a expedição de Cabinda e os príncipes e potentados do lugar, 26 jul. 1783" Arquivo Histórico Ultramarino (AHU), Angola, cx. 67, doc. 8. Mambuco era o título dado aos administradores do litoral, enquanto manfuca era o responsável pelo comércio e pela cobrança de impostos.

2 "Proposições feitas ao embaixador do Rei Mambuco na tarde de 11 de novembro de 1783, no quartel [de Santa Maria de] de Cabinda”. AHU, Angola, cx. 67, doc. 45. ${ }^{3}$ AHU, Angola, cx. 119, doc. 2.

4 "Ofício do Conde de Galveas ao Conde dos Arcos, governador da Bahia, Rio de Janeiro, 2 ago. 1811” Biblioteca Nacional/Divisão de Manuscritos (BNDM), II - 33, $29,23$.

${ }^{5}$ Em resposta à embaixada do Daomé, a Coroa portuguesa enviou dois padres com o objetivo de converter o soberano local, Adarunzá VIII, ao catolicismo. O relato da viagem desses embaixadores (Vicente Ferreira Pires e Cypriano Pires Sardinha) pode ser lido na obra de Clado Ribeiro de Lessa, Crônica de uma embaixada lusobrasileira à Costa d'Africa em fins do século XVIII, incluindo o texto da viagem de África em o Reino de Dabomé, escrita pelo padre Vicente Ferreira Pires no ano de 1800 e até o presente inédita. São Paulo: Cia. Ed. Nacional, 1957.

Anos 90, Porto Alegre, v. 15 n. 27, p. 107-123, jul. 2008 


\section{Jaime Rodrigues}

6 "Ofício do Conde de Galveas ao Conde dos Arcos", doc. cit.

${ }^{7}$ As considerações sobre os diversos tratados assinados entre os governos ingleses, portugueses e brasileiros, desde 1810, baseiam-se em VERGER (1987, p. 300-317).

8 "Ofício de Antonio Saldanha da Gama ao Visconde de Anadia, 17 ago. 1807" AHU, Angola, cx. 118, doc. 17.

${ }^{9}$ AHU, Angola, cx. 118, doc. 19.

10 "Carta do Rei Adoxa ao rei [sic] de Portugal, Onim, 12 mar. 1812" BNDM, I - 46, 15,11 .

${ }^{11} \mathrm{O}$ tráfico como questão diplomática e de direito internacional entre as nações já foi abordado por diversos autores. Ver, em especial, COVER, Robert. Justice accused: antislavery and the judicial process. New Haven/London: Yale University Press, 1975, e Bethell, Leslie. A abolição do tráfico de escravos no Brasil. Rio de Janeiro: Expressão e Cultura; São Paulo: Edusp, 1976.

\section{Referências bibliográficas}

KLEIN, Herbert. Tráfico de escravos. In: Instituto Brasileiro de Geografia e Estatística. Estatísticas históricas do Brasil. Rio de Janeiro: IBGE, 1987.

LARA, Silvia H. Uma embaixada africana na América portuguesa. In: JANCSÓ, István; KANTOR, Íris (orgs.). Festa: cultura e sociabilidade na América portuguesa. v. 1. São Paulo: IMESP/Edusp/Hucitec/FAPESP, 2001, p. 151-165.

PÉLISSIER. História das campanhas de Angola: resistência e revoltas (1845-1941). Lisboa: Imprensa Universitária, Editorial Estampa, 1986.

RODRIGUES, José Honório. Independência: revolução e contra-revolução. v. 5: a política internacional. Rio de Janeiro: Francisco Alves, 1975.

VERGER, Pierre. Fluxo e refluxo do tráfico de escravos entre o Golfo de Benin e a Babia de Todos os Santos dos séculos XVII ao XIX. São Paulo: Corrupio, 1987.

Recebido em 11/08/2008 Autor convidado 
